\title{
Clinical and Prognostic Significances of Cytokeratin 19 and KIT Expression in Surgically Resectable Pancreatic Neuroendocrine Tumors
}

\author{
Eun-Mi Son $\cdot$ Joo Young Kim ${ }^{1}$ \\ Soyeon An · Ki-Byung Song ${ }^{2}$ \\ Song Cheol $\mathrm{Kim}^{2}$ - Eunsil Yu \\ Seung-Mo Hong
}

Department of Pathology, Asan Medical Center, University of Ulsan College of Medicine; 'Department of Pathology, Korea University Anam Hospital, Korea University College of Medicine; '2Department of Surgery, Asan Medica Center, University of Ulsan College of Medicine, Seoul, Korea

Received: August 12, 2014

Revised: October 22, 2014

Accepted: October 23, 2014

\section{Corresponding Author}

Seung-Mo Hong, M.D.

Department of Pathology, University of Ulsan

College of Medicine, Asan Medical Center, 88

Olympic-ro 43-gil, Songpa-gu, Seoul 138-736,

Korea

Tel: +82-2-3010-4558

Fax: $+82-2-472-7898$

E-mail: smhong28@gmail.com
Background: Pancreatic neuroendocrine tumors (PanNETs) are malignant endocrine neoplasms that present diverse clinical behaviors. Therefore, identification of biomarkers of PanNETs is important for stratification of the prognosis of PanNET patients. Recently, cytokeratin 19 (CK19) and KIT expression were reported to have prognostic significance in PanNET patients. Methods: To identify their prognostic significance, CK19 and KIT protein expression were assessed in 182 surgically resected PanNETs and compared with clinicopathologic factors. Results: Of 182 PanNETs cases, CK19 and KIT expression was noted in 97 (53.3\%) and 16 (8.8\%) cases, respectively. PanNET patients with CK19 expression had larger tumors $(p=.006)$, higher World Health Organization $(\mathrm{WHO})$ grade $(p=.002)$ and $\mathrm{pT}$ classification $(\mathrm{p}<.001)$, increased distant metastasis $(p=.004)$, and lymphovascular $(p=.012)$ and perineural $(p=.019)$ invasion. Similarly, those with KIT expression had larger tumors $(p=.030)$, higher WHO grade $(p=.001)$, advanced pT classification $(p<.001)$, distant metastasis $(p=.001)$, and lymphovascular invasion $(p=.014)$. The 5 -year survival rate for PanNET patients with KIT expression was significantly lower (62\%) than that of patients without KIT expression $(77 \%, p=.011)$, as determined by univariate but not by multivariate analyses. Conclusions: CK19 and KIT expression correlate with higher metastatic potential and advanced disease stage, and KIT expression is associated with worse survival in PanNET patients.

Key Words: Pancreas; Neuroendocrine tumors; Keratin-19; KIT; Immunohistochemistry
Pancreatic neuroendocrine tumors (PanNETs) are malignant tumors of endocrine origin from the pancreas and comprise $1.3 \%$ to $2.8 \%$ of all pancreatic neoplasms. ${ }^{1}$ The incidence and prevalence of PanNETs have increased over the past decades according to data from the Surveillance, Epidemiology, and End Results (SEER) study. ${ }^{2}$ Compared with ductal adenocarcinoma of the pancreas, PanNETs are generally considered to have indolent behaviors with diverse clinical features ranging from benign to highly malignant. ${ }^{3,4}$ Therefore, predicting the clinical behavior of PanNETs is very difficult.

A recent whole-exome sequencing study demonstrated unique driver mutations in PanNETs, such as MEN1, ATRX, and DA$X X{ }^{5}$ In addition, although the frequencies are low, several genes in the mammalian target of rapamycin pathway, including PTEN, TSC2, and PIK3CA, were also reported to be involved in the tumorigenesis of PanNETs. ${ }^{5}$ The expression status of some of these proteins was shown to be related to the survival of PanNET patients. For example, the losses of ATRX and DAXX were associated with worse survival. On the other hand, loss of PTEN expression was associated with better survival in PanNET patients. ${ }^{6,7}$

The new World Health Organization (WHO) grading scheme and the TNM staging system from the American Joint Committee on Cancer (AJCC) and the International Union for Cancer Control (UICC) provide reliable guidelines for the prognosis and treatment of PanNET patients. ${ }^{4,8}$ However, except for pathologic grade and TNM stage, few prognostic biomarkers for PanNETs have been reported. Hence, the identification of prognostic biomarkers for PanNETs will provide more precise information regarding PanNET patient survival after surgical resection. ${ }^{2,-13}$ 
Several previous studies have reported the prognostic significance of cytokeratin 19 (CK19), KIT, cyclooxygenase 2, and CD99 in PanNET patients. ${ }^{2,9-13}$ However, there have not been any validation studies for these markers, except for CK19 expression. ${ }^{2,9,11,12}$ The aims of this study were to determine the clinical and prognostic significance of CK19 and KIT expression in surgically resected PanNET patients using tissue microarray immunohistochemical staining.

\section{MATERIALS AND METHODS}

After approval (2014-0580) from the Institutional Review Board, 182 patients with primary PanNETs who underwent surgical resection at our institution from 1995 to 2013 were selected from the files of the Department of Pathology. Medical records were reviewed to evaluate clinical data, such as age, sex, symptoms, and follow-up data. Pathologic information, including tumor size, extension, metastases to regional lymph nodes, distant metastases, and lymphovascular and perineural invasions were carefully reviewed. Hematoxylin and eosin-stained slides were independently reviewed by three pathologists (S.-M.H., J.Y.K., and E.-M.S.). All PanNET cases were confirmed by immunohistochemical staining using neuroendocrine markers, synaptophysin, chromogranin, and/or CD56. Immunohistochemical staining for synaptophysin and chromogranin was performed in 144 and 138 cases, respectively. All 144 cases (100\%) were positive for synaptophysin, and 113 of 138 (81.9\%) cases were positive for chromogranin. All PanNET cases were re-classified into grades 1, 2, or 3 based on mitotic counts (per 10 high-power fields) and the Ki-67 labeling index according to the scheme of the 2010 WHO classification. ${ }^{8}$ Tumor extension was assessed based on the T classification of the 2010 AJCC/UICC cancer staging system.

Tissue microarrarys (TMAs) were constructed using three 2mm-diameter tumor cores from donor blocks using a manual tissue microarryer (Uni TMA Co., Ltd., Seoul, Korea). The sections of TMAs were stained using an automatic immunohistochemistry staining device (Benchmark XT, Ventana Medical System, Tucson, AZ, USA). Briefly, 5 - $\mu$-thick formaldehydefixed paraffin-embedded tissue sections were transferred onto adhesive slides and dried at $62^{\circ} \mathrm{C}$ for 30 minutes. Standard heat epitope retrieval was performed for 30 minutes in ethylene diamine tetraacetic acid, $\mathrm{pH} 8.0$, in the autostainer. The samples were then incubated with antibodies against KIT (1:400, DakoCytomation, Glostrup, Denmark) and CK19 (1:100, Cell Marque, Rocklin, CA, USA). The sections were subsequently incubated with biotinylated anti-mouse immunoglobulins, peroxidase-labeled streptavidin (LSAB kit, DakoCytomation), and 3,30-diaminobenzidine. Negative control samples were processed without the primary antibody. Slides were counterstained with Harris hematoxylin. Nuclear labeling of intra-tumoral mast cells was used as an internal positive control for KIT immunohistochemical staining. Normal pancreatic acinar cells, ductal epithelial cells, and islet cells were negative for KIT staining, while mast cells in the pancreatic parenchyma were positive (Fig. 1A). Membranous immunolabeling in normal pancreatic ductal epithelial cells and centroacinar cells was used as an internal positive control for CK19 staining. Normal pancreatic islet cells and acinar cells were negative for CK19 staining (Fig. 1B). Sections demonstrating $>5 \%$ positivity for KIT- and CK19-labeled tumor cells were considered to be positive, as previously described. $^{2,13}$

SPSS ver. 18.0 (SPSS, Chicago, IL, USA) was used for the statistical analysis. The overall survival time was calculated from the date of diagnosis of PanNET to that of death from any cause. The overall survival rate was calculated with the Kaplan-Meier method, and the associations between overall survival rate and clinicopathologic factors were compared using the log-rank test. Correlations between KIT and CK19 expression and other prognostic factors were analyzed using chi-square and Fisher exact tests. Possible prognostic factors associated with survival probability were calculated by the Cox's proportional hazard regression model. A $\mathrm{p}<.05$ was considered statistically significant.

\section{RESULTS}

Of a total of 182 PanNET patients, $44.5 \%$ (81 cases) were men, $55.5 \%$ (101 cases) were women, and the mean age was $51.4 \pm 13.10$ years. The mean tumor size was $3.06 \pm 2.31 \mathrm{~cm}$. Tumors were classified as functional tumors if they were associated with the distinct clinical manifestations of hormonal alterations, including hypoglycemia, sweating, or syncope; 45 cases (24.7\%) were consequently classified as functional PanNETs. There were 71 head (39.0\%), 7 uncinate (3.8\%), 29 body (15.9\%), 67 tail (36.8\%), 2 head to body (1.1\%), and 6 body to tail (3.3\%) tumors. Using the TNM staging system, PanNETs were classified as pT1 in $74(40.7 \%)$, pT2 in $47(25.8 \%)$, and pT3 in 61 (33.5\%) cases. Because only surgically resected PanNETs were included in the study, pT4 tumors were not included. Lymphovascular and perineural invasion was noted in 48 (26.4\%) and 27 (14.8\%) cases, respectively. Evaluation of the lymph nodes was possible in 99 cases (54.4\%), and lymph node metastasis 


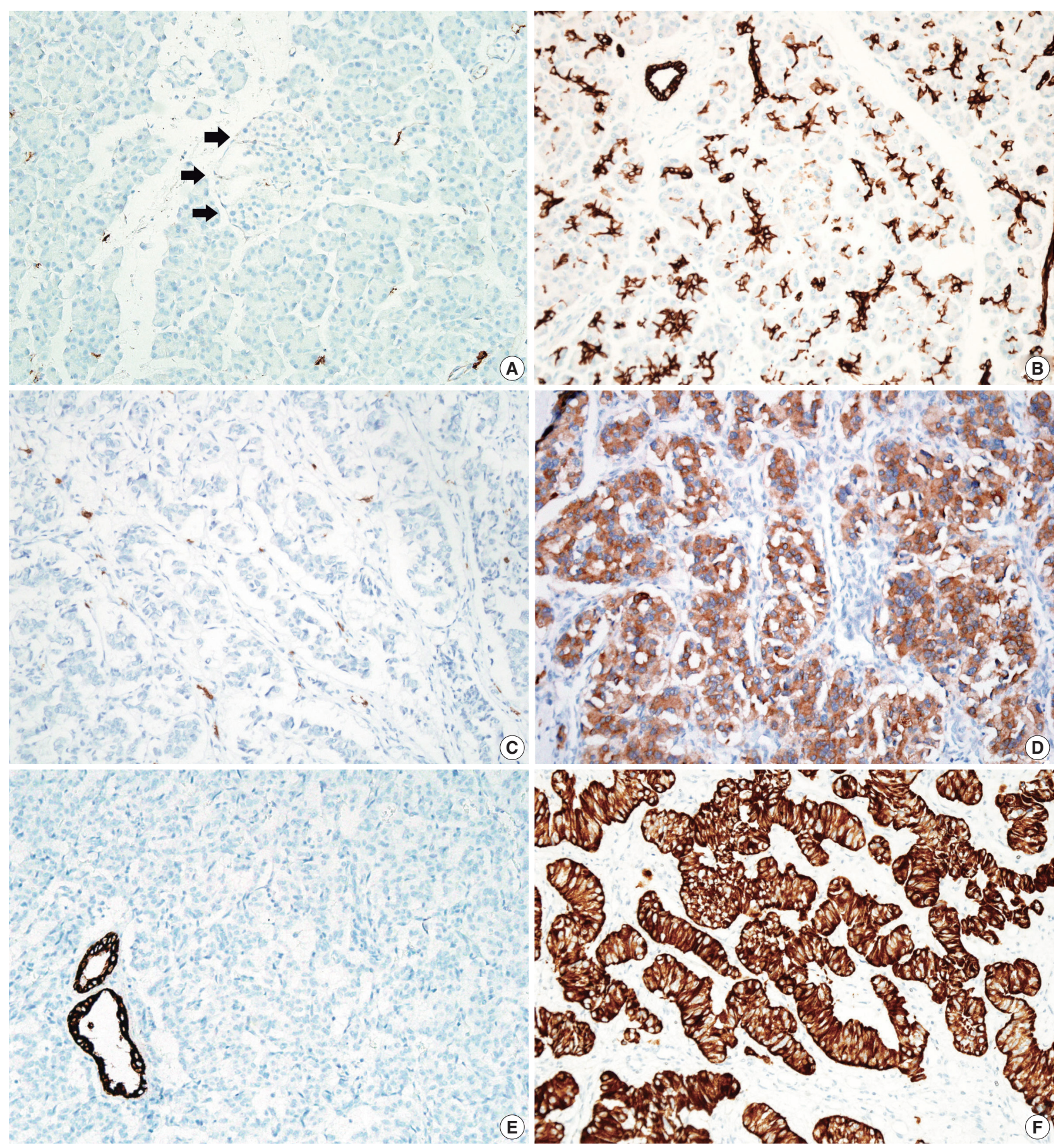

Fig. 1. Representative images of KIT and cytokeratin 19 (CK19) staining. (A) Normal acinar cell, ductal epithelial cells, and islet cells (arrows) of the pancreas are negative for KIT staining, while mast cells in the pancreatic parenchyma are positive for KIT staining. (B) Membranous CK19 immunolabeling is noted in the normal centroacinar cell and the ductal epithelial cells, while islet cells are not stained. Negative (C) and positive (D) KIT expression in a pancreatic neuroendocrine tumor. (E) Negative CK19 expression is observed in a pancreatic neuroendocrine tumor, while entrapped normal pancreatic ductal cells are positive for CK19. (F) Positive CK19 expression in a pancreatic neuroendocrine tumor.

was present in 29 cases (15.9\%). Distant metastasis was observed in 36 cases (19.8\%), and liver was the most common site of these distant metastases (32 cases, 88.9\%). Adequate follow-up of survival information was available in 181 patients, with a me- dian follow-up period of 30 months (range, 1 to 142 months), and 153 patients (84.1\%) were alive and 28 patients (15.3\%) had died; 9 of these patients died of an unrelated cause.

KIT expression was observed in 16 of 182 PanNETs (8.8\%) 
Table 1. Correlations between KIT or CK19 expression and clinicopathological factors

\begin{tabular}{|c|c|c|c|c|c|c|c|c|}
\hline \multirow{2}{*}{ Parameter } & & \multirow{2}{*}{ Total } & \multicolumn{2}{|c|}{ KIT expression } & \multirow{2}{*}{$p$-value } & \multicolumn{2}{|c|}{ CK19 expression } & \multirow{2}{*}{$p$-value } \\
\hline & & & Positive & Negative & & Positive & Negative & \\
\hline \multirow[t]{2}{*}{ Sex } & Male & 81 & $11(13.6)$ & $70(86.4)$ & .063 & $49(60.5)$ & $32(39.5)$ & .081 \\
\hline & Female & 101 & $5(5.0)$ & $96(95.0)$ & & $48(47.5)$ & $53(52.5)$ & \\
\hline \multirow[t]{2}{*}{ Age (yr) } & $<60$ & 127 & $11(8.7)$ & $116(91.3)$ & 1.000 & $68(53.5)$ & $59(46.5)$ & .919 \\
\hline & $\geq 60$ & 55 & $5(9.1)$ & $50(90.9)$ & & $29(52.7)$ & $26(47.3)$ & \\
\hline \multirow[t]{2}{*}{ Function status } & Functioning & 45 & $1(2.2)$ & $44(97.8)$ & .125 & $12(26.7)$ & $33(73.3)$ & $<.001$ \\
\hline & Non-functioning & 137 & $15(10.9)$ & $122(89.1)$ & & $85(62.0)$ & $52(38.0)$ & \\
\hline \multirow[t]{2}{*}{ Tumor size $(\mathrm{cm})$} & $\leq 2$ & 81 & $3(3.7)$ & 78 (96.3) & .030 & $34(42.0)$ & $47(58.0)$ & .006 \\
\hline & $>2$ & 101 & $13(12.9)$ & $88(87.1)$ & & $63(62.4)$ & $38(37.6)$ & \\
\hline \multirow[t]{2}{*}{ Extrapancreatic extension } & Absent & 120 & $4(3.3)$ & $116(96.7)$ & $<.001$ & $52(43.3)$ & $68(56.7)$ & $<.001$ \\
\hline & Present & 62 & $12(19.4)$ & $50(80.6)$ & & $45(72.6)$ & $17(27.4)$ & \\
\hline \multirow{3}{*}{ pT classification } & pT1 & 74 & $1(1.4)$ & 73 (98.6) & $<.001$ & $30(40.5)$ & $44(59.5)$ & $<.001$ \\
\hline & pT2 & 47 & $3(6.3)$ & $44(93.6)$ & & $23(48.9)$ & $24(51.1)$ & \\
\hline & pT3 & 61 & $12(19.7)$ & 49 (80.3) & & $45(71.4)$ & $18(28.6)$ & \\
\hline \multirow[t]{2}{*}{ Lymph node metastasis } & Absent & 89 & $24(27.0)$ & $65(73.0)$ & .152 & $39(63.9)$ & $31(81.6)$ & .061 \\
\hline & Present & 10 & $5(50.0)$ & $5(50.0)$ & & $31(81.6)$ & 7 (18.4) & \\
\hline \multirow[t]{2}{*}{ Distant metastasis } & Absent & 146 & $7(4.8)$ & $139(95.2)$ & .001 & 70 (47.9) & $76(52.1)$ & .004 \\
\hline & Present & 36 & $9(25.0)$ & $27(75.0)$ & & $27(75.0)$ & $9(25.0)$ & \\
\hline \multirow[t]{3}{*}{ WHO grade } & Grade 1 & 125 & $6(4.8)$ & $119(95.2)$ & .001 & $59(47.2)$ & $66(52.8)$ & .002 \\
\hline & Grade 2 & 48 & $7(14.6)$ & $41(85.4)$ & & $29(60.4)$ & $19(39.6)$ & \\
\hline & Grade 3 & 9 & $3(33.3)$ & $6(66.7)$ & & $9(90.9)$ & 0 & \\
\hline \multirow[t]{2}{*}{ Lymphovascular invasion } & Absent & 134 & $7(5.2)$ & $127(94.8)$ & .014 & $64(47.8)$ & $70(52.2)$ & .012 \\
\hline & Present & 48 & $9(18.8)$ & 39 (81.3) & & $33(68.8)$ & 15 (31.3) & \\
\hline \multirow[t]{2}{*}{ Perineural invasion } & Absent & 155 & $11(7.1)$ & $144(92.9)$ & .067 & 77 (49.7) & 78 (50.3) & .019 \\
\hline & Present & 27 & 5 (18.5) & $22(81.5)$ & & $20(74.1)$ & $7(25.9)$ & \\
\hline
\end{tabular}

Values are presented as number (\%).

CK9, cytokeratin 9; WHO, World Health Organization.

(Fig. 1D) and CK19 expression was noted in 97 cases (53.3\%) (Fig. 1F). All 16 PanNET cases that showed KIT expression were also positive for CK19. The associations between KIT or CK19 expression and clinicopathological factors are summarized in Table 1. KIT expression was more frequently observed in larger PanNETs $(\mathrm{p}=.030)$, those with extrapancreatic extension $(\mathrm{p}<.001)$, advanced $\mathrm{pT}$ classification $(\mathrm{p}<.001)$, distant metastasis $(\mathrm{p}=.001)$, higher $\mathrm{WHO}$ grade $(\mathrm{p}=.001)$, and lymphovascular invasion $(\mathrm{p}=.014)$. There was no statistically significant correlation between KIT expression and sex, age, functional status, lymph node metastasis, expression of synaptophysin and chromogranin, or perineural invasion.

CK19 expression was more commonly observed in functioning PanNETs $(\mathrm{p}<.001)$, larger tumors $(\mathrm{p}=.006)$, extrapancreatic extension ( $\mathrm{p}<.001)$, advanced $\mathrm{pT}$ classification $(\mathrm{p}<.001)$, lymph node metastasis $(\mathrm{p}=.009)$, distant metastasis $(\mathrm{p}=.004)$, higher WHO grade $(\mathrm{p}=.002)$, and lymphovascular $(\mathrm{p}=.012)$ and perineural $(\mathrm{p}=.019)$ invasion. There was no statistically significant correlation between CK19 expression and sex, age, or expression of synaptophysin and chromogranin. The overall survival rate of PanNET patients with KIT expression was significantly lower (5-year survival rate, 62\%) than that of patients without KIT expression $(77 \%, \mathrm{p}=.011)$ (Fig. 2A). However, the overall survival rate of PanNET patients with CK19 expression (5-year survival rate, $74 \%$ ) was not significantly different from that of patients lacking CK19 expression (79\%, $\mathrm{p}=.242)$ (Fig. 2B).

The relationships between the survival of PanNET patients and other clinicopathologic factors are summarized in Table 2. Of these clinicopathologic factors, increased age $(\mathrm{p}<.001)$, extrapancreatic extension $(\mathrm{p}=.003)$, increased $\mathrm{pT}$ classification $(\mathrm{p}=.009)$, lymph node metastasis $(\mathrm{p}=.026)$, distant metastasis $(\mathrm{p}=.003)$, and higher $\mathrm{WHO}$ grade $(\mathrm{p}<.001)$ were correlated with worse survival. In contrast, overall survival was not correlated with sex, functional status, or lymphovascular and perineural invasion.

Multivariate analysis was performed to assess which factors remained independent predictors of survival after adjusting for factors that were found to be significant by univariate analysis. Only WHO grade remained as an independent prognostic factor $(\mathrm{p}=.001)$ (Table 3). Conversely, KIT expression, pT classification, and lymph node and distant metastases were not found to be independent prognostic factors in the present model. 

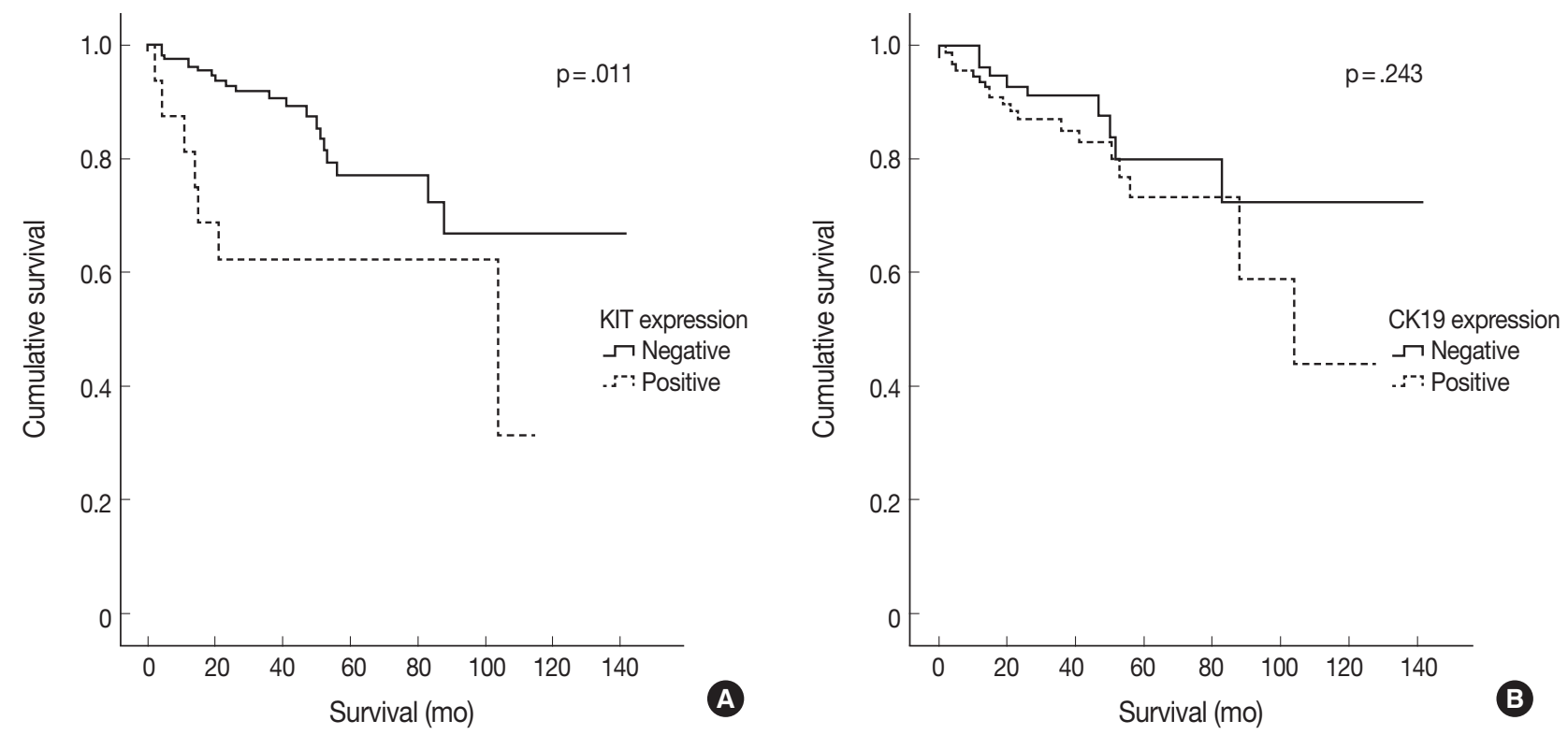

Fig. 2. Kaplan-Meier survival analysis of pancreatic neuroendocrine tumor patients according to KIT (A) and cytokeratin 19 (CK19) (B) expression status. (A) The overall 5-year survival rate for pancreatic neuroendocrine tumor (PanNET) patients with KIT expression is significantly lower (62\%) than that of patients without KIT expression (77\%, $p=.011)$. (B) The overall 5-year survival rate for PanNET patients with CK19 expression (74\%) is not significantly different from that of those without CK19 expression $(79 \%, p=.243)$.

Table 2. Univariate analysis of overall survival by clinicopathologic features with PanNETs

\begin{tabular}{|c|c|c|c|}
\hline Parameter & & $\begin{array}{c}5 \text {-Year survival } \\
\text { rate }(\%)\end{array}$ & $\mathrm{p}$-value \\
\hline Sex & $\begin{array}{l}\text { Male } \\
\text { Female }\end{array}$ & $\begin{array}{l}82 \\
72\end{array}$ & .673 \\
\hline Age (yr) & $\begin{array}{l}<60 \\
\geq 60\end{array}$ & $\begin{array}{l}87 \\
50\end{array}$ & $<.001$ \\
\hline Function status & $\begin{array}{l}\text { Functioning tumors } \\
\text { Non-functioning }\end{array}$ & $\begin{array}{l}91 \\
72\end{array}$ & .349 \\
\hline Tumor size (cm) & $\begin{array}{l}\leq 2 \\
>2\end{array}$ & $\begin{array}{l}85 \\
72\end{array}$ & .171 \\
\hline Extrapancreatic extension & $\begin{array}{l}\text { Absent } \\
\text { Present }\end{array}$ & $\begin{array}{l}82 \\
66\end{array}$ & .003 \\
\hline pT classification & $\begin{array}{l}\text { pT1 } \\
\text { pT2 } \\
\text { pT3 }\end{array}$ & $\begin{array}{l}88 \\
78 \\
65\end{array}$ & .009 \\
\hline Lymph node metastasis & $\begin{array}{l}\text { Absent } \\
\text { Present }\end{array}$ & $\begin{array}{l}78 \\
56\end{array}$ & .026 \\
\hline Distant metastasis & $\begin{array}{l}\text { Absent } \\
\text { Present }\end{array}$ & $\begin{array}{l}80 \\
63\end{array}$ & .003 \\
\hline WHO grade & $\begin{array}{l}\text { Grade } 1 \\
\text { Grade } 2 \\
\text { Grade } 3\end{array}$ & $\begin{array}{r}86 \\
62 \\
0\end{array}$ & $<.001$ \\
\hline KIT expression & $\begin{array}{l}\text { Negative } \\
\text { Positive }\end{array}$ & $\begin{array}{l}77 \\
62\end{array}$ & .011 \\
\hline CK19 expression & $\begin{array}{l}\text { Negative } \\
\text { Positive }\end{array}$ & $\begin{array}{l}79 \\
74\end{array}$ & .243 \\
\hline Lymphovascular invasion & $\begin{array}{l}\text { Absent } \\
\text { Present }\end{array}$ & $\begin{array}{l}80 \\
68\end{array}$ & .071 \\
\hline Perineural invasion & $\begin{array}{l}\text { Absent } \\
\text { Present }\end{array}$ & $\begin{array}{l}79 \\
63\end{array}$ & .152 \\
\hline
\end{tabular}

PanNET, pancreatic neuroendocrine tumor; WHO, World Health Organization; CK19, cytokertain 19.
Table 3. Multivariate analysis of overall survival by clinicopathologic features with pancreatic neuroendocrine tumors

\begin{tabular}{|c|c|c|c|c|c|}
\hline \multirow[t]{2}{*}{ Parameter } & & \multirow{2}{*}{$\begin{array}{c}\text { Hazard } \\
\text { ratio }\end{array}$} & \multicolumn{2}{|c|}{$\begin{array}{l}\text { 95\% Confidence } \\
\text { interval }\end{array}$} & \multirow[t]{2}{*}{ p-value } \\
\hline & & & Low & Upper & \\
\hline KIT expression & & 2.09 & 0.69 & 6.33 & .195 \\
\hline pT classification & $\begin{array}{l}\text { T1 } \\
\text { T2 } \\
\text { T3 }\end{array}$ & $\begin{array}{l}1 \\
1.73 \\
1.84\end{array}$ & $\begin{array}{c}- \\
0.31 \\
0.31\end{array}$ & $\begin{array}{r}- \\
9.51 \\
11.01\end{array}$ & $\begin{array}{l}.786 \\
.529 \\
.503\end{array}$ \\
\hline Lymph node metastasis & & 1.53 & 0.51 & 4.60 & .446 \\
\hline Distant metastasis & & 0.5 & 0.17 & 1.46 & .204 \\
\hline WHO Grade & $\begin{array}{l}1 \\
2 \\
3\end{array}$ & $\begin{array}{c}1 \\
2.41 \\
18.27\end{array}$ & $\begin{array}{c}- \\
0.84 \\
4.12\end{array}$ & $\begin{array}{r}- \\
6.89 \\
80.99\end{array}$ & $\begin{array}{r}.001 \\
.102 \\
<.001\end{array}$ \\
\hline
\end{tabular}

WHO, World Health Organization.

\section{DISCUSSION}

KIT is a cytoplasmic membrane-bound receptor tyrosine kinase and a stem cell marker. Activation of KIT signaling has been found to mediate cell survival, migration, and proliferation. ${ }^{14}$ Signaling from KIT is crucial for normal hematopoiesis, pigmentation, fertility, and gut movement. Deregulated KIT kinase activity has been observed in a number of pathological conditions, including small cell lung cancer, breast cancer, colon cancer, melanoma, gastrointestinal stromal tumors, and allergy. ${ }^{14} \mathrm{KIT}$ is involved in $\beta$-cell development and survival and in regulation of glucose metabolism of the endocrine pancreas 
via receptor phosphorylation. ${ }^{15-19}$ Normally, KIT expression in the endocrine pancreas is present during the embryonic and early fetal periods; however, it is not expressed in the adult pancreas. ${ }^{15,19}$ Thus, KIT expression in the endocrine pancreas is considered to be a stem cell feature. Several pancreatic neoplasms with KIT expression have been reported, including ductal adenocarcinomas, intraductal papillary mucinous neoplasms, mucinous cystic neoplasms, serous cyst adenomas, and neuroendocrine tumors, although the proportion of pancreatic neoplasms expressing KIT was small. ${ }^{20,21}$

Several previous studies have reported KIT expression in PanNETs, with $22 \%$ to $46 \%$ of PanNETs expressing KIT., ${ }^{2,1322}$ In the present study, we observed KIT expression in 8.8\% (16/182) of PanNET cases. This is a significantly lower percentage than reported in previous studies and might be related to ethnicity, as all previous studies were performed with Caucasians while all the cases included in the present study were Koreans. KIT expression is generally associated with worse prognosis in cancers of other organs, including colorectal, stomach, bile duct, and endometrial cancers, and malignant melanomas of the vulva. ${ }^{23-27}$ In contrast, KIT expression in patients with neuroblastomas and hepatocellular carcinomas is an indicator of good survival. ${ }^{28,29}$ There have been controversies with respect to the prognostic significance of KIT expression in PanNETs. ${ }^{2,13}$ Zhang et al. ${ }^{13}$ reported that KIT expression was an independent worse prognostic factor for PanNETs, while Han et al. ${ }^{2}$ observed no significant survival differences based on KIT expression. PanNETs with KIT expression resulted in significantly worse survival than those without KIT expression in the present study; a finding that concurs with those of the previous study of Zhang et al..$^{13} \mathrm{~A}$ plausible explanation for the worse prognosis in PanNET cases with KIT expression is that these PanNETs may possess stem cell features. The mechanisms of KIT expression in PanNETs are unknown. One previous study demonstrated no KIT mutations in exons 9 and 11 in any of the 21 examined PanNETs expressing KIT. ${ }^{13}$ Plausible explanations for KIT overexpression without mutations in exons 9 and 11 include KIT mutations that occur in other exons.

CK19 is one of a 20-member cytokeratin family that encompasses the intermediate filaments of epithelial cells. In the early embryonic stage, endocrine cells in the pancreas strongly express CK19. This expression is gradually lost such that most islet cells no longer express CK19 by 41 gestational weeks, whereas all ductal and acinar cells maintain CK19 labeling. ${ }^{30,31}$

Previous studies have demonstrated CK19 expression in 49\% to $70 \%$ of PanNETs. ${ }^{2,9,12,13}$ In the present study, CK19 expres- sion was found in $53.3 \%$ (97/182 cases) of PanNETs, which is concordant with the results of previous studies. In previous studies, CK19-expressing PanNETs were associated with aggressive pathologic features, including increased tumor size, mitoses, lymphovascular invasion, and necrosis. ${ }^{9-12}$ In accordance with the results of these previous studies, we also observed that PanNETs expressing CK19 were associated with larger tumor size, higher WHO grade, higher TNM stage, and lymphovascular and perineural invasions. Several previous studies have demonstrated that PanNET patients with CK19 expression had decreased survival rates. ${ }^{9-12}$ However, in contrast to the results of previous studies, we did not observe any prognostic significance of CK19 expression in PanNET patients, although CK19 expression was related with aggressive clinical behavior in PanNET patients.

In summary, we observed that 1) subsets of PanNETs express KIT or CK19, 2) KIT and CK19 expression was associated with aggressive behavior of PanNETs, and 3) KIT expression was correlated with decreased survival of PanNET patients but was not an independent prognostic factor.

\section{Conflicts of Interest}

No potential conflict of interest relevant to this article was reported.

\section{REFERENCES}

1. Yao JC, Eisner MP, Leary C, et al. Population-based study of islet cell carcinoma. Ann Surg Oncol 2007; 14: 3492-500.

2. Han X, Zhao J, Ji Y, Xu X, Lou W. Expression of CK19 and KIT in resectable pancreatic neuroendocrine tumors. Tumour Biol 2013; 34: $2881-9$.

3. Reichert M, Rustgi AK. Pancreatic ductal cells in development, regeneration, and neoplasia. J Clin Invest 2011; 121: 4572-8.

4. Strosberg JR, Cheema A, Weber J, Han G, Coppola D, Kvols LK. Prognostic validity of a novel American Joint Committee on Cancer Staging Classification for pancreatic neuroendocrine tumors. J Clin Oncol 2011; 29: 3044-9.

5. Jiao Y, Shi C, Edil BH, et al. DAXX/ATRX, MEN1, and mTOR pathway genes are frequently altered in pancreatic neuroendocrine tumors. Science 2011; 331: 1199-203.

6. Krausch M, Raffel A, Anlauf M, et al. Loss of PTEN expression in neuroendocrine pancreatic tumors. Horm Metab Res 2011; 43: 86571.

7. Marinoni I, Kurrer AS, Vassella E, et al. Loss of DAXX and ATRX are associated with chromosome instability and reduced survival 
of patients with pancreatic neuroendocrine tumors. Gastroenterology 2014; 146: 453-60.

8. Bosnan FT, Carneiro F, Hruban RH, Theise ND. WHO classification of tumours of the digestive system. 4th ed. Lyon: IARC Press, 2010.

9. Ali A, Serra S, Asa SL, Chetty R. The predictive value of CK19 and CD99 in pancreatic endocrine tumors. Am J Surg Pathol 2006; 30: 1588-94.

10. Jonkers YM, Claessen SM, Perren A, et al. DNA copy number status is a powerful predictor of poor survival in endocrine pancreatic tumor patients. Endocr Relat Cancer 2007; 14: 769-79.

11. La Rosa S, Rigoli E, Uccella S, Novario R, Capella C. Prognostic and biological significance of cytokeratin 19 in pancreatic endocrine tumours. Histopathology 2007; 50: 597-606.

12. Schmitt AM, Anlauf M, Rousson V, et al. WHO 2004 criteria and CK19 are reliable prognostic markers in pancreatic endocrine tumors. Am J Surg Pathol 2007; 31: 1677-82.

13. Zhang L, Smyrk TC, Oliveira AM, et al. KIT is an independent prognostic marker for pancreatic endocrine tumors: a finding derived from analysis of islet cell differentiation markers. Am J Surg Pathol 2009; 33: 1562-9.

14. Lennartsson J, Rönnstrand L. Stem cell factor receptor/c-Kit: from basic science to clinical implications. Physiol Rev 2012; 92: 1619-49.

15. Li J, Quirt J, Do HQ, et al. Expression of c-Kit receptor tyrosine kinase and effect on beta-cell development in the human fetal pancreas. Am J Physiol Endocrinol Metab 2007; 293: E475-83.

16. Ashman LK. The biology of stem cell factor and its receptor C-kit. Int J Biochem Cell Biol 1999; 31: 1037-51.

17. Feng ZC, Li J, Turco BA, Riopel M, Yee SP, Wang R. Critical role of c-Kit in beta cell function: increased insulin secretion and protection against diabetes in a mouse model. Diabetologia 2012; 55: 2214-25.

18. Kaligin MS, Gumerova AA, Titova MA, Andreeva DI, Sharipova ÉI, Kiiasov AP. C-kit is a marker of human pancreatic endocrinocyte stem cells. Morfologiia 2011; 140: 32-7.

19. Liu W, Chen L, Zhu J, Rodgers GP. The glycoprotein hGC-1 binds to cadherin and lectins. Exp Cell Res 2006; 312: 1785-97.

20. Kimura W, Ma J, Takeshita A, et al. Analysis of c-kit protein expres- sion in pancreatic neoplasms and its implication for prognosis. Hepatogastroenterology 2007; 54: 2203-8.

21. Ohike N, Sato M, Hisayuki T, et al. Immunohistochemical analysis of nestin and c-kit and their significance in pancreatic tumors. Pathol Int 2007; 57: 589-93.

22. Yasuda A, Sawai $H$, Takahashi $H$, et al. The stem cell factor/c-kit receptor pathway enhances proliferation and invasion of pancreatic cancer cells. Mol Cancer 2006; 5: 46.

23. Sammarco I, Capurso G, Coppola L, et al. Expression of the protooncogene c-KIT in normal and tumor tissues from colorectal carcinoma patients. Int J Colorectal Dis 2004; 19: 545-53.

24. Heinzelmann-Schwarz VA, Nixdorf S, Valadan M, et al. A clinicopathological review of 33 patients with vulvar melanoma identifies c-KIT as a prognostic marker. Int J Mol Med 2014; 33: 784-94.

25. Kurokawa Y, Matsuura N, Kawabata R, et al. Prognostic impact of major receptor tyrosine kinase expression in gastric cancer. Ann Surg Oncol 2014; 21 Suppl 4: S584-90.

26. Hong SM, Hwang I, Song DE, Choi J, Yu E. Clinical and prognostic significances of nuclear and cytoplasmic KIT expressions in extrahepatic bile duct carcinomas. Mod Pathol 2007; 20: 562-9.

27. Scobie JV, Acs G, Bandera CA, et al. C-kit immunoreactivity in endometrial adenocarcinomas and its clinicopathologic significance. Int J Gynecol Pathol 2003; 22: 149-55.

28. Chung CY, Yeh KT, Hsu NC, et al. Expression of c-kit protooncogene in human hepatocellular carcinoma. Cancer Lett 2005; 217: 231-6.

29. Krams M, Parwaresch R, Sipos B, Heidorn K, Harms D, Rudolph P. Expression of the c-kit receptor characterizes a subset of neuroblastomas with favorable prognosis. Oncogene 2004; 23: 588-95.

30. Piper K, Brickwood S, Turnpenny LW, et al. Beta cell differentiation during early human pancreas development. J Endocrinol 2004; 181: 11-23.

31. Bouwens L, Lu WG, De Krijger R. Proliferation and differentiation in the human fetal endocrine pancreas. Diabetologia 1997; 40: 398404. 